Thermal Management for High Power Lithium-Ion Battery by Minichannel

\title{
Aluminum Tubes
}

\author{
Chuanjin Lan ${ }^{1}, \mathrm{Jian}_{\mathrm{Xu}}{ }^{1}, \mathrm{Yu} \mathrm{Qiao}^{2}$, and Yanbao $\mathrm{Ma}^{1 *}$ \\ ${ }^{1}$ School of Engineering, University of California, Merced, Merced, CA95343, USA \\ ${ }^{2}$ Department of Structural Engineering, University of California San Diego, La Jolla, Ca 92093, USA
}

Corresponding author:

Yanbao Ma

School of Engineering

University of California, Merced

Phone: (209) 228-4046

Email:yma5@ucmerced.edu 


\title{
Thermal Management for High Power Lithium-Ion Battery by Minichannel
}

\author{
Aluminum Tubes \\ Chuanjin $\operatorname{Lan}^{1}$, Jian $\mathrm{Xu}^{1}, \mathrm{Yu} \mathrm{Qiao}^{2}$, and Yanbao Ma ${ }^{1 *}$ \\ ${ }^{1}$ School of Engineering, University of California, Merced, Merced, CA95343, USA \\ ${ }^{2}$ Department of Structural Engineering, University of California San Diego, La Jolla, Ca 92093, USA
}

\begin{abstract}
Lithium-ion batteries are widely used for battery electric (all-electric) vehicles (BEV) and hybrid electric vehicles (HEV) due to their high energy and power density. Battery thermal management system (BTMS) is crucial for the performance, lifetime, and safety of lithium-ion batteries. In this paper, a novel design of BTMS based on aluminum minichannel tubes is developed and applied on a single prismatic Li-ion cell under different discharge rates. Parametric studies are conducted to investigate the performance of the BTMS using different flow rates and configurations. With minichannel cooling, the maximum cell temperature at $1 \mathrm{C}$ discharge rate is less than $27.8^{\circ} \mathrm{C}$ and temperature difference across the cell is less than $0.80{ }^{\circ} \mathrm{C}$ using flow rate at $0.20 \mathrm{~L} / \mathrm{min}$, at the expense of $8.69 \mathrm{e}-6 \mathrm{~W}$ pumping power. At higher discharge rates, e.g., $1.5 \mathrm{C}$ and $2 \mathrm{C}$, higher flow rates are required to maintain the same temperature rise and temperature difference. The flow rate needed is $0.8 \mathrm{~L} / \mathrm{min}$ for $1.5 \mathrm{C}$ and $2.0 \mathrm{~L} / \mathrm{min}$ for $2 \mathrm{C}$, while the required pumping power is $4.23 \mathrm{e}-4 \mathrm{~W}$ and $5.27 \mathrm{e}-3 \mathrm{~W}$, respectively. The uniform temperature distribution $\left(<1{ }^{\circ} \mathrm{C}\right)$ inside the single cell and efficient pumping power demonstrates that the minichannel cooling system provides a promising solution for the BTMS.
\end{abstract}

Keywords: Electric vehicle, Lithium ion battery, Thermal management, Minichannel cooling 


\section{Introduction}

While the traditional transportation vehicle with internal combustion engine contributes about $13 \%$ of annual world greenhouse gas (GHG) emissions [1], battery electric vehicles (BEV) and hybrid electric vehicles (HEV) are emerging replacement for traditional vehicles to reduce GHG emissions [2]. EVs and HEVs are not only cleaner and more environmentally friendly but are also more economically effective as the operating cost is reduced dramatically [3]. Due to its high energy density, high power density, long life, and environmental friendliness, Li-ion batteries are widely used for BEVs and HEVs. However, the poor-performance at low temperature, the degradation of electrodes at high temperature, and the safety issues due to thermal runaway associated with the Li-ion batteries will directly influence the performance, cost, reliability, and the safety of EVs. Therefore, the battery thermal management system (BTMS) is crucial for the EVs [4-10].

During the thermal management study for lithium-ion batteries, adequate knowledge of heat generation and thermal behavior inside the battery is required to predict the battery temperature. Studies have been done on the thermal modeling of batteries at different operating conditions, i.e., at normal discharge rates or thermal abuses [8, 11-20]. For normal operating conditions, Pesaran et al. [11] developed a lumped capacitance battery thermal model to predict the thermal performance and impact of the temperature on vehicle level performance. Based on this lumped model, thermal behavior of modules and packs were evaluated. In another study by Chen et al. [12], a detailed three-dimensional thermal model was developed to examine the thermal behavior of a lithium-ion battery, considering the layered-structure of the cell stacks, the case of a battery pack, and the gap between both elements. Using this detailed model, the asymmetric temperature profile and the anomaly of temperature distribution on the surface can be simulated precisely. Besides these modeling techniques for normal conditions, different models were also developed for oven exposure testing. An one-dimensional predictive model for 18650 lithium-ion cell was developed by Hatchard et al. using thermal properties of the cells and the kinetics of jelly-roll material 
decomposition reactions [13]. To consider geometrical features, a three-dimensional model was developed by Kim et al. to determine the local hot spot propagation through the cell [14]. Their results showed that cell size greatly affected the thermal behavior of a cell due to different heat transfer area per unit volume. Guo et al. proposed another three-dimensional model to predict the thermal abuse performances of lithium-ion batteries with high capacity, and analyzed the temperature distribution under the abuse conditions [15]. The model predictions were compared to experimental test results and a good agreement can be seen. For other abuse situations, thermal modeling for battery pack has also been developed in one-dimensional lumped model [16] and further in three-dimensional model [17]. The thermal runaway caused by nail penetration was experimentally studied by Doh et al. [18] and Chiu et al. [19], who also modeled the complex reactions and mechanisms during the thermal runaway.

With profound understanding of the thermal behavior of battery cells at different operating conditions, different battery thermal management systems (BTMS), e.g., air cooling, liquid cooling, and phase change material (PCM) cooling, have been applied to avoid the safety issues from thermal aspect and to maintain the optimal operating temperature. Air cooling with different structures has been applied by manipulating the position of the air-inlet and the air-outlet along with longitudinal or horizontal battery pack [21-26]. However, compared with the effectiveness of the passive cooling by PCM, the active forced air cooling is not a proper thermal management system to keep the temperature of the cell in the desirable operating range without expending significant fan power [27]. Another advantage of the PCM cooling is that the generated heat during the discharge can be stored as latent heat in the PCM and transferred back to the cell module during the relaxation. Therefore, the battery temperature can be kept above the environment temperature for a long time, which can increase the overall energy efficiency of the battery system [28-31]. Compared with the PCM cooling and air cooling, liquid cooling system can provide more effective heat transfer with different channel designs [32-34]. The cold-plate structure of the S-type with guide plates was introduced by Zhang et al. to avoid the heat concentration and increase the heat transfer area [32]. To enhance the performance of the conventional channel with minimum pressure penalty, an 
oblique minichannel liquid cold plate was developed by Jin et al. to cool down the EV batteries without over-designing the cooling system[33]. In spite of these studies, a safer and more cost-effective thermal management system is still required.

In present study, a new battery thermal management system using aluminum minichannel tubes was designed. Different designs of tube system were parametrically studied at different discharging rates. The numerical modeling of the battery and cooling system design is introduced in next section. To examine the performance of this BTMS at different discharge rates, different designs of tube system are applied and the results are shown in the third section. The conclusion on the applicability of the minichannels cooling system is given in the last section.

\section{Method}

\subsection{Physical problem}

The computational domain consists of a prismatic geometry as the representative of one single battery cell, the minichannel cooling system, and the fluid. The dimensions for the cell are $173 \mathrm{~mm}(z$ : height) by $168 \mathrm{~mm}$ ( $x$ : width) by $39 \mathrm{~mm}$ ( $y$ : depth), and the capacity is 55 Ampere-hour. The heat generation inside battery is assumed uniform but the thermal conductivity is anisotropic. Other properties of the battery are assumed homogenous. The aluminum minichannel tubes wrap around three sides of the battery, as shown in Fig.1(a)-(d). The geometry of the tubes is shown in Fig.1(e): the height of channel (h) is $3 \mathrm{~mm}$, and width (w) is $3 \mathrm{~mm}$. The thickness of aluminum between the outer surface and channel $(\delta)$ is $1 \mathrm{~mm}$, and the thickness between two neighbor channels will be twice of $\delta$ [35]. With the minichannel cooling system, the temperature distribution across the battery is studied at different discharge rates. The desired temperature range for battery performance is between $15^{\circ} \mathrm{C}$ and $35^{\circ} \mathrm{C}$ [36]. If the battery temperature is below this range, battery performance will be lowered due to poor ion transport. On the other hand, 
temperature higher than that range will cause faster side reactions, leading to higher dissipation rates of cyclable lithium and active materials.

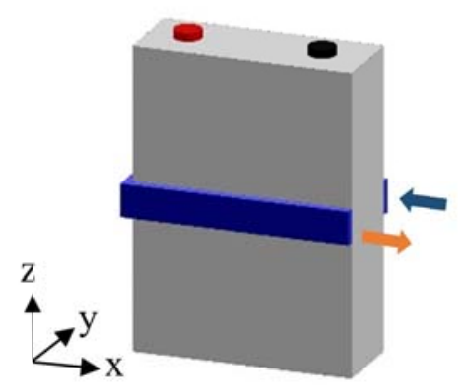

(a) channels 1 by 4

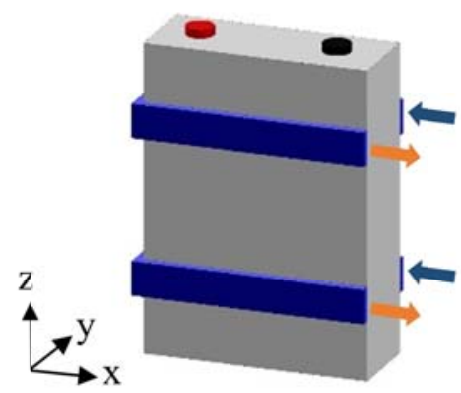

(c) channels 2 by 4

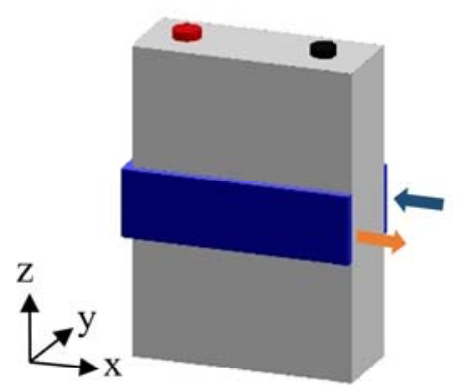

(b) channels 1 by 8

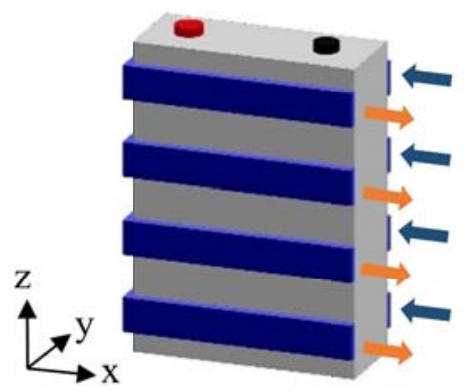

(d) channels 4 by 4

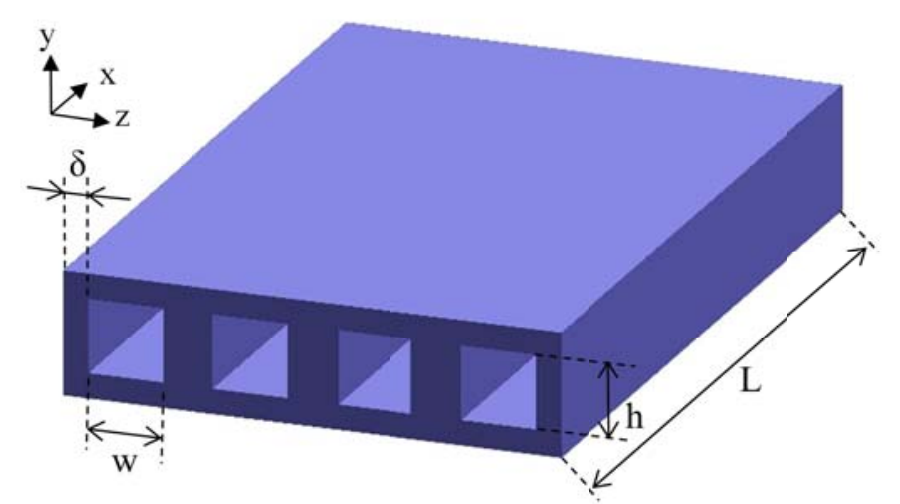

(e) Details of the minichannel geometry

Fig.1 Different designs of minichannel cooling system: (a), one strip with four minichannels; (b), one strip with eight minichannels; (c), two strips with four minichannels each; (d), four strips with four minichannels each (blue arrows indicate the inflow direction and orange ones represent outflow direction); (e), details of the minichannel geometry. 


\subsection{Governing equations}

The energy conservation equation of the battery cell is given as follows:

$$
\rho_{b} C_{b} \frac{\partial T_{b}}{\partial t}=\frac{\partial}{\partial x}\left(k_{x} \frac{\partial T_{b}}{\partial x}\right)+\frac{\partial}{\partial y}\left(k_{y} \frac{\partial T_{b}}{\partial y}\right)+\frac{\partial}{\partial z}\left(k_{z} \frac{\partial T_{b}}{\partial z}\right)+Q_{b}
$$

where $\rho_{b}$ and $C_{b}$ are the average density and average specific heat of battery, respectively; $k_{x}, k_{z}$ are the inplane thermal conductivity along width and height direction, and $k_{y}$ is the cross-plane thermal conductivity in depth direction. These parameters of battery material are given in Table.1 $[13,19] . Q_{b}$ is the uniform volumetric heat generation rate across the whole battery. Their value at different discharge rates for the lumped model of single cell are extracted from Xu's work [22], as listed in Table. 2.

Table.1. Material properties

\begin{tabular}{ccc}
\hline Parameter & Aluminum & Battery \\
\hline $\mathrm{k}\left(\mathrm{W} \mathrm{m}^{-1} \mathrm{~K}^{-1}\right)$ & 238 & 3.4 (cross-plane) $/$ \\
& & 34.0 (in plane) \\
$\rho\left(\mathrm{kg} \mathrm{m}^{-3}\right)$ & 2700 & 1700 \\
$\mathrm{C}_{\mathrm{p}}\left(\mathrm{J} \mathrm{kg}^{-1} \mathrm{~K}^{-1}\right)$ & 900 & 830 \\
\hline
\end{tabular}

Table.2. Heat generation rate of 55Ah lithium-ion battery monomer at different discharge rates

\begin{tabular}{cccc}
\hline Discharge rate & $1 \mathrm{C}$ & $1.5 \mathrm{C}$ & $2 \mathrm{C}$ \\
\hline Heat generation rate $Q_{b}(\mathrm{~W})$ & 7.60 & 15.60 & 23.89 \\
\hline
\end{tabular}


Liquid water is used as the cooling fluid inside the aluminum minichannels. The energy conservation equation for water is:

$$
\rho_{w} C_{w} \frac{\partial T_{w}}{\partial t}+\nabla \cdot\left(\rho_{w} C_{w} \vec{v} T_{w}\right)=\nabla \cdot\left(k_{w} \nabla T_{w}\right)
$$

where $\rho_{w}, C_{w}$ and $k_{w}$ are the average density, specific heat and thermal conductivity of water, respectively.

$T_{w}$ is the water temperature and $\vec{v}$ is the velocity vector of water. The motion of incompressible liquid water is governed by the mass and momentum conservation equations:

$$
\begin{gathered}
\nabla \cdot \vec{v}=0 \\
\rho_{\mathrm{w}}\left[\frac{\partial \vec{v}}{\partial t}+(\vec{v} \cdot \nabla) \vec{v}\right]=-\nabla \mathrm{P}+\mu \nabla^{2} \vec{v}
\end{gathered}
$$

where $P$ and $\mu$ are the static pressure and dynamic viscosity of water.

\subsection{Initial and Boundary Conditions}

The initial temperatures of the battery, the cooling channels, and the water are set at $27^{\circ} \mathrm{C}$. At flow inlets, the velocity and temperature of water are assumed to be uniform and constant. For the flow outlet, a constant zero pressure is specified and an outflow boundary condition is used for energy equations. No slip boundary condition is used for the inside surfaces of minichannels. Thermal contact resistance between aluminum minichannels and battery is not taken into consideration in this study. Since the battery is usually located in a narrow and tight space, the air surrounding the battery can be quickly heated up without effective ventilation. Therefore, in this study, convective cooling by surrounding air is assumed to be negligible in the situation of no fans installed. In other words, thermal insulation boundary condition is applied on all the outer surfaces of the battery. As a result, the minichannel cooling is the only way for the heat dissipation of the battery. 


\subsection{Numerical Method}

The commercial finite element software package COMSOL is used to solve the conjugate heat transfer problem. Each simulation is performed in two steps. In the first step, flow fields are solved using a stationary iterative solver with relative tolerance set as 0.001 , since the effect of heat transfer on flow fields is quite small and can be neglected (water density is assumed constant). After the convergence of flow fields, in the second step, the heat transfer in both solid domain and flow domain are solved together. Direct solver is used for time dependent simulation and the absolute tolerance is set as 0.001 . Time step is set as one second since temperature field advances gradually and monotonously. In this way, the simulation can be much faster than solving coupled flow and heat equations.

\subsection{Model Validation}

In this study, free tetrahedral mesh is used for the mesh construction. A mesh independence check is first performed. Most elements are assigned to the fluid domain and the meshes at two corners are specially refined. Sparse mesh is used for the heat transfer in the solid battery domain. Two meshes with different number of elements are used for the mesh independence check. The geometry in Fig.1 (a) is used for the validation case. Uniform inlet velocity is set as $0.023 \mathrm{~m} / \mathrm{s}$ and the discharge rate is $1 \mathrm{C}\left(Q_{b}=7.60 \mathrm{~W}\right)$. For the fine mesh, 418192 elements are used in total, 303492 of which are used for fluid domain. For the coarse one, 202778 elements are used in total, 135312 of which are used for fluid domain. For the results, the maximum velocity obtained by fine mesh is $0.0378 \mathrm{~m} / \mathrm{s}$ and pressure drop is $34.54 \mathrm{~Pa}$. The maximum temperature in the battery is $34.87{ }^{\circ} \mathrm{C}$. Using the coarse mesh, the maximum velocity obtained is $0.0374 \mathrm{~m} / \mathrm{s}$ and pressure drop is $35.63 \mathrm{~Pa}$. The maximum temperature in the battery is $34.57{ }^{\circ} \mathrm{C}$. The difference in the maximum velocity and difference in maximum temperature are both $1 \%$, while the pressure difference is about 3\%. These results validate the mesh independence and the coarse mesh design is used for the other cases in this study. 
After validating the mesh design, the simulation of heat transfer and laminar flow also needs validation. As for the heat transfer simulation, energy conservation can be checked for the whole system. The input heat generation rate is $7.60 \mathrm{~W}$ from the battery at $1 \mathrm{C}$ discharge rate, and the thermal power carried away by the water is $7.67 \mathrm{~W}$, which is the only way for heat loss from the system. The difference is $1 \%$, thus validating the results for energy conservation. As for the laminar flows inside minichannels, the friction loss at the end of the long section before reaching the bend can be compared with analytical solutions. The long straight section of the minichannel is long enough for the flow to be fully developed before reaching the bend. For fully developed laminar flow inside rectangular channels with geometrical aspect ratio $\alpha(w / h)$, the friction factor $(f)$ can be predicted by [37]:

$$
(f \mathrm{Re})_{f d}=24\left(1-1.3553 / \alpha+1.9467 / \alpha^{2}-1.7012 / \alpha^{3}+0.9564 / \alpha^{4}-0.2537 / \alpha^{5}\right)
$$

where $R e$ is Reynolds number and $f$ is Darcy friction factor, respectively, given as: $\operatorname{Re}=\rho_{w} U_{0} D_{h} / \mu$, and $f=\left(\Delta P * D_{h}\right) /\left(\frac{1}{2} \rho_{w} U_{0}^{2} * 4 L\right) . D_{h}$ is the hydraulic diameter of the rectangular minichannel, $U_{0}$ is the average velocity at the channel inlet, $\mu$ is the dynamic viscosity of water, $\Delta P$ is the pressure drop, and $L$ is the length. For a square duct, $(f \mathrm{Re})_{f d}$ is calculated to be 14.23 as $\alpha=1$. The result from simulations is $f \operatorname{Re}=13.36$, which is $6 \%$ different from predictions.

In the end, the pressure drop of laminar flow through the whole minichannel with two $90^{\circ}$ bends is calculated and the result is compared with theoretical predictions. To account for the entrance length effect, apparent friction factor is calculated for both the developing and fully developed laminar flow regions in the channel, given as

$$
f_{a p p} \operatorname{Re}=\left[\left\{3.2 /\left(x^{+}\right)^{0.57}\right\}^{2}+(f \mathrm{Re})_{f d}^{2}\right]^{\frac{1}{2}}
$$


In this equation entrance length is defined as: $x^{+}=L /\left(D_{h} \cdot \mathrm{Re}\right)$. More details for theoretical predictions are given in Liu's work [38]. As for the excess pressure loss due to $90^{\circ}$ square bends, for slow flow or negligibly small Re, it is linear in the velocity rather than quadratic, given as [39]:

$$
\Delta \mathrm{P}_{\text {excess }}=\mathrm{K}_{\mathrm{L}} \frac{\mu \mathrm{U}_{0}}{\mathrm{D}_{\mathrm{h}}}
$$

where $K_{L}$ is coefficient given for different bend geometries, which is 4.2 for a 3D square corner [39]. To validate the pressure loss based on this equation, a small inlet velocity is applied as $\mathrm{U}_{0}=0.00579 \mathrm{~m} / \mathrm{s}$. The total pressure loss calculated from simulation is $6.58 \mathrm{~Pa}$, which is $6 \%$ different from the predicted value 7.03Pa based on Eq.(5), (6) and (7). All the above mentioned tests for energy conservation and pressure drop comparison indicate that the model used in this study is valid.

\section{Results and Discussions}

After validating the model, the effects of different minichannel designs at different discharge rates, as well as the effects of different flow rates are studied here. The maximum temperature of the battery and the temperature difference between the maximum temperature and minimum temperature of the battery, denoted as $T_{\max }$ and $T_{\text {diff, }}$, will be mainly discussed for different cases. Uniformity index $T_{u n i}$, which is used to quantify the temperature difference inside the whole battery is also discussed. It is defined as:

$$
\mathrm{T}_{\text {uni }}=\mathrm{T}_{\text {diff }} / \mathrm{T}_{\mathrm{avg}}
$$

where $T_{a v g}$ is the average temperature of the whole battery. According to the definition, the smaller these values are, the better performance it is for the thermal management system design.

\subsection{Thermal management at discharge rate of $1 \mathrm{C}\left(Q_{b}=7.60 \mathrm{~W}\right)$}

\subsubsection{Different designs for minichannel system}


Four different minichannel cooling systems with different number of strips and different number of minichannels are chosen to study the effect of different geometrical design, as shown in Fig.1(a)-(d). In design (a), one strip with four minichannels is wrapped in the middle of battery; in design (b), one strip with eight minichannels is used; in design (c), two strips with four minichannels each are located in upper and lower part of the battery, respectively; in design (d), four strips with four minichannels each are distributed uniformly. All the flow inlets are set on one side of battery and flow outlets on the other side.

The maximum temperatures of the battery $T_{\max }$ for the four different designs are shown in Fig.2(a). The discharge rate is fixed at $1 \mathrm{C}\left(Q_{b}=7.60 \mathrm{~W}\right)$, and the flow rate is $0.05 \mathrm{~L} / \mathrm{min}$. Since the total number of minichannels is different for designs (a)-(d), the inlet flow velocity varies accordingly for different designs due to different total cross-section areas. Design (a) which uses one strip with four minichannels shows the highest temperature rise, from $27.0^{\circ} \mathrm{C}$ to $30.08{ }^{\circ} \mathrm{C}$ after 1 hour of discharging. Compared to design (a), $T_{\max }$ for design (b) (one strip with eight minichannels) changes from $27.0^{\circ} \mathrm{C}$ to $29.75{ }^{\circ} \mathrm{C}$. This indicates that a strip with more minichannels can reduce the temperature rise, though the flow rate is lower. For design (c), which has the same total number of minichannels as design (b), $T_{\max }$ increases from $27.0{ }^{\circ} \mathrm{C}$ to $29.35{ }^{\circ} \mathrm{C}$. The temperature increase is smaller than that of design (b). From this comparison, it can be seen that a distributed distribution of minichannels has better thermal management performance than concentrating all minichannels at one place. For design (d), which has four strips evenly distributed, $T_{\max }$ has the minimum increase from $27.0^{\circ} \mathrm{C}$ to $29.20^{\circ} \mathrm{C}$. These results show that the design using more minichannels and more distributed distribution has the minimum temperature increase. This is reasonable since the heat can be more easily dissipated by minichannels when the contact areas are larger and more distributed. 


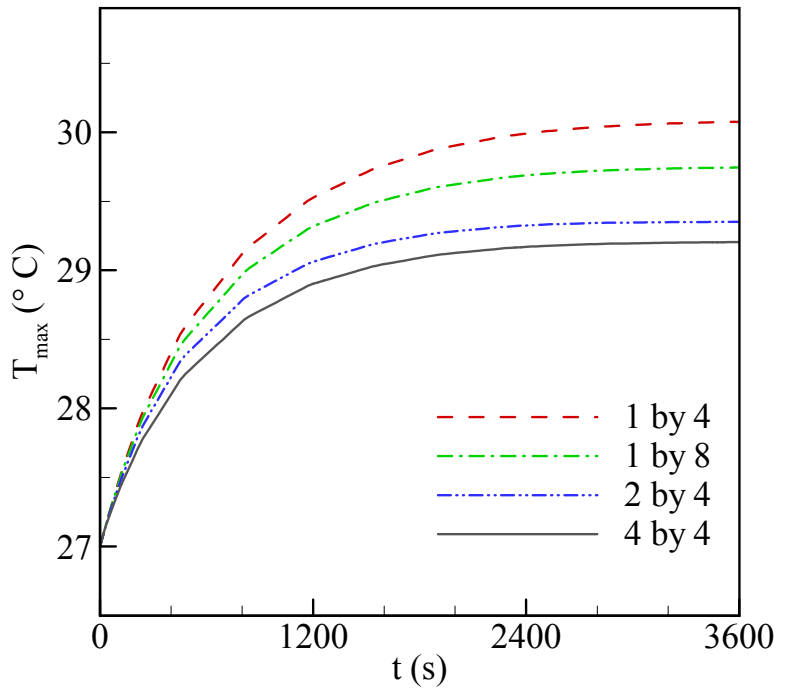

(a)

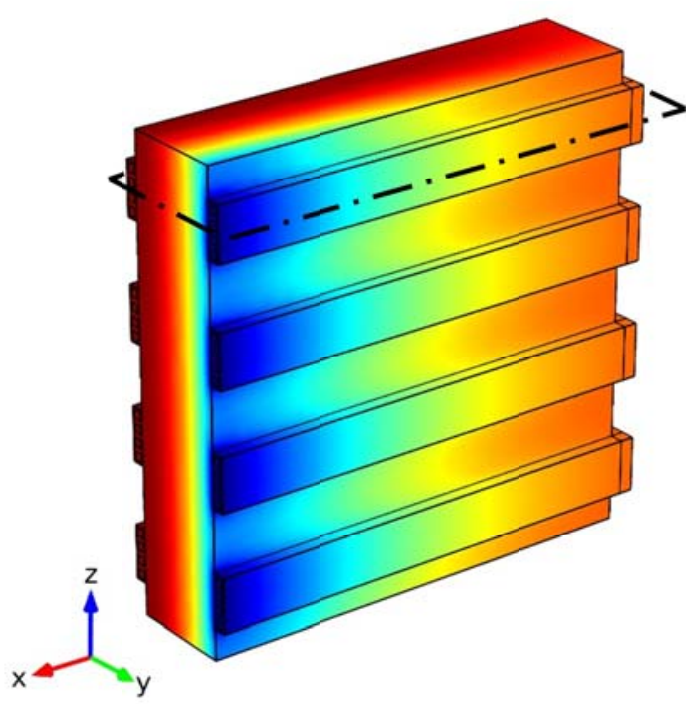

(c)

28

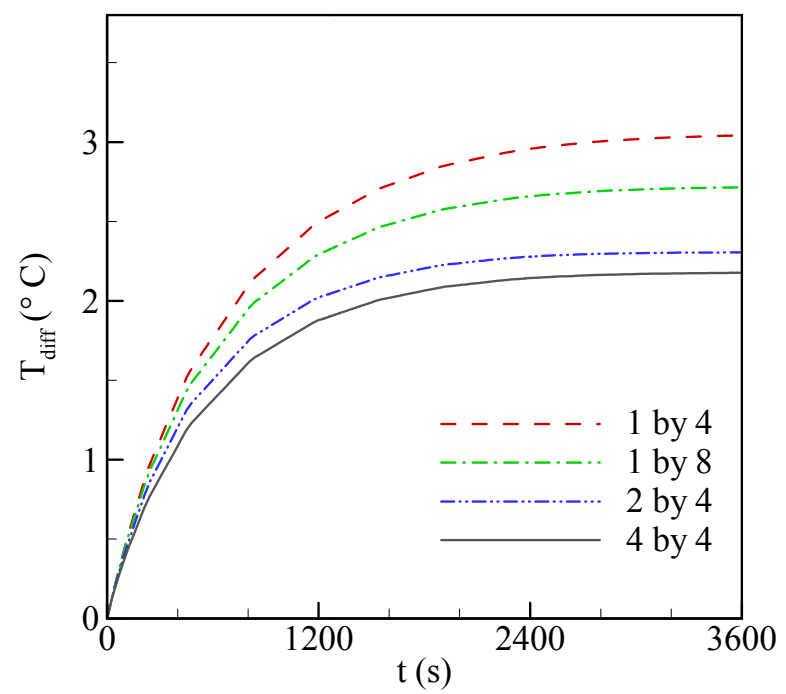

(b)

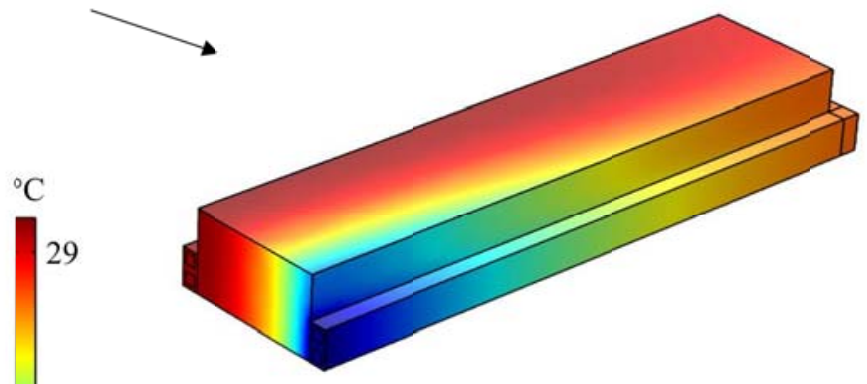

(d)

Fig.2 (a) Temporal history of maximum temperature, (b) temporal history of temperature difference, (c) temperature distribution after 1 hour of discharging at $1 \mathrm{C}\left(Q_{b}=7.60 \mathrm{~W}\right)$ with flow rate at $0.05 \mathrm{~L} / \mathrm{min}$, (d) temperature distribution of the top one eighth of the battery. Since no heat flux goes through the dashed plane in (c) due to symmetry and the thermal insulated outer surfaces of the battery, the simulation can be performed on this much smaller geometry than the original whole shape, thus saving computational resources and showing enlarged views. 
The temperature differences $T_{\text {diff }}$ across the whole battery are shown in Fig.2(b). It can be seen that the temporal change of $T_{\text {diff }}$ is similar to $T_{\max }$ for each corresponding case. This is because, near the minichannels inlet, the local battery temperature is always close to the inlet water temperature since the battery and the inlet water are only separated by a thin layer of aluminum (Fig.2(c)). However, near the minichannels outlet, as the water is warmed up, the heat dissipation efficiency for battery is reduced and maximum battery temperature occurs. Since the local battery temperature near the minichannels inlet is the minimum battery temperature, and remained almost unchanged, the change of temperature difference depends mainly on the maximum temperature variation. $T_{d i f f}, T_{\max }$ and $T_{u n i}$ after 1 hour of discharging at 1C are shown in Table.3, as well as pressure drop and pumping power required. The pumping power for design (a) is more than 5 times larger than design (b), and more than 23 times larger than design (d). From the comparison in Table.3, the design (d) requires minimum pumping power and obtains the best thermal management performance (minimum $T_{d i f f}, T_{\max }$ and $T_{u n i}$ ), while the only shortcoming is requiring most channel materials for the cost issue. So design (d) will be used for all the remaining subsections.

Table.3 Comparison of pressure drop, pumping power, temperature difference and maximum temperature rise for different designs at discharge rate of $1 \mathrm{C}\left(Q_{b}=7.60 \mathrm{~W}\right)$ with flow rate at $0.05 \mathrm{~L} / \mathrm{min}$

\begin{tabular}{cccccc}
\hline Case & $\boldsymbol{\Delta P}(\mathbf{P a})$ & Pumping Power $(\mathbf{W})$ & $\boldsymbol{T}_{\text {diff }}\left({ }^{\circ} \mathrm{C}\right)$ & $\boldsymbol{T}_{\boldsymbol{m a x}}\left({ }^{\circ} \mathrm{C}\right)$ & $\boldsymbol{T}_{\text {uni }}$ \\
\hline 1 by 4 & 41.8 & $8.71 \mathrm{e}-6$ & 3.04 & 30.08 & 0.102 \\
1 by 8 & 15.8 & $1.66 \mathrm{e}-6$ & 2.72 & 29.75 & 0.093 \\
2 by 4 & 15.8 & $1.66 \mathrm{e}-6$ & 2.30 & 29.35 & 0.079 \\
4 by 4 & 7.03 & $3.66 \mathrm{e}-7$ & 2.18 & 29.20 & 0.076 \\
\hline
\end{tabular}

\subsubsection{Different flow directions for performance enhancement}

Based on design (d) in Fig.1(d), five designs with different flow direction are developed to study the effect of flow direction, as shown in Fig.3. The blue arrows indicate the flow inlets, and the orange arrows indicate the flow outlet. The design 'Direction 1' has been used in previous subsection 3.1.1. 


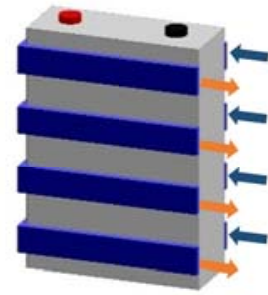

(a) Direction 1

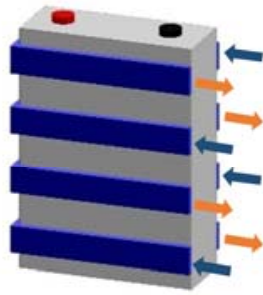

(b) Direction 2

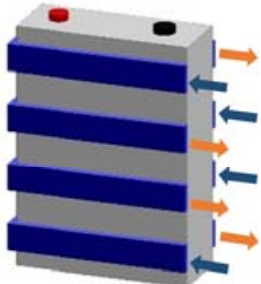

(c) Direction 3

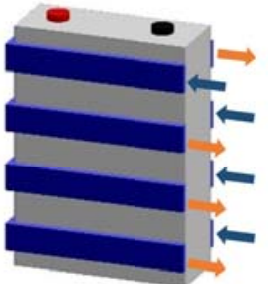

(d) Direction 4

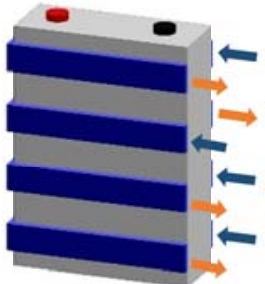

(e) Direction 5

Fig.3 Design with different flow directions. Blue arrows indicate the flow inlet and orange ones represent flow outlet.

The temporal variations of $T_{\max }$ and $T_{\text {diff }}$ are shown in Fig.4. Similar trends for $T_{\max }$ and $T_{\text {diff }}$ are observed for each case. Among the five designs, case 'Direction 1' obtains the minimum $T_{\max }$ and $T_{\text {diff. Considering }}$ the complexity and cost of the inlet manifold, the case 'Direction 1' is also the best choice. The worst thermal performance occurs for case 'Direction 2', which has alternative flow direction. For the other three cases, variations of $T_{\max }$ and $T_{\text {diff }}$ show close performance. Based on these results, the design 'Direction 1' will be used for all the remaining subsections.

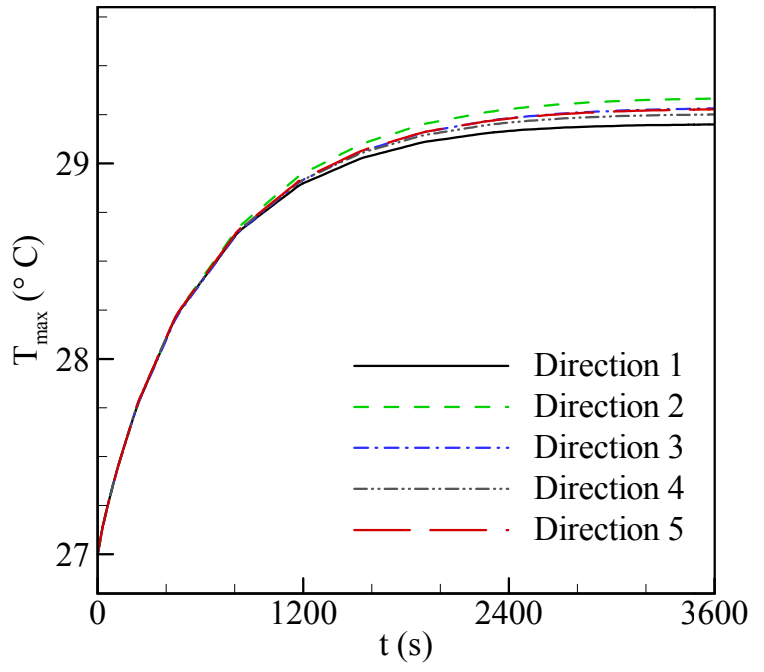

(a)

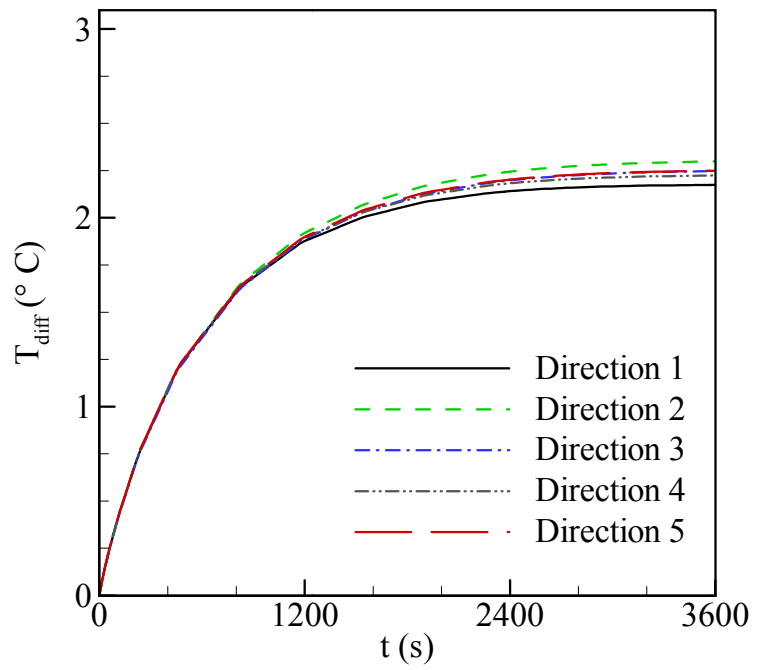

(b)

Fig.4 Temporal history of (a) maximum temperature and (b) temperature difference using different flow directions, at discharge rate of $1 \mathrm{C}\left(Q_{b}=7.60 \mathrm{~W}\right)$. 


\subsubsection{Different flow rates for performance enhancement}

Since the pressure drop and the required pumping power are quite small as observed in Table.3, the flow rate can be increased to further improve the thermal management performance. In this study, the flow is kept in laminar regime.

The maximum temperatures and temperature differences of the battery at different flow rates are shown in Fig.5. It can be seen that $T_{\max }$ and $T_{\text {diff }}$ get lower as the flow rate increases. Using flow rates as $0.15 \mathrm{~L} / \mathrm{min}$ and $0.20 \mathrm{~L} / \mathrm{min}$, the $T_{\max }$ becomes stable in no longer than 1200 seconds. From Fig.5(c), it can be seen that the high temperature area of the battery is close to the minichannel outlet, since the water near the outlet is already heated up and the water temperature is close to the maximum temperature of the battery. When flow rate is $0.15 \mathrm{~L} / \mathrm{min}$, the $T_{\max }$ is kept at $28{ }^{\circ} \mathrm{C}$ and $T_{\text {diff }}$ is less than $1{ }^{\circ} \mathrm{C}$. Once flow rate is increased to $0.20 \mathrm{~L} / \mathrm{min}, T_{\max }$ gets to $27.81^{\circ} \mathrm{C}$ and $T_{\text {diff }}$ becomes $0.80{ }^{\circ} \mathrm{C}$ after 1 hour of discharging at $1 \mathrm{C}$ $\left(Q_{b}=7.60 \mathrm{~W}\right)$. As the flow rate increases, the uniformity index $T_{u n i}$ also reduces as $T_{\max }$ and $T_{\text {diff, }}$, as shown

in Table.4. These results demonstrate that the minichannel cooling system can maintain $T_{\text {diff }}$ to be less than $1{ }^{\circ} \mathrm{C}$, and it only requires $4.28 \mathrm{e}-6 \mathrm{~W}$ and $8.69 \mathrm{e}-6 \mathrm{~W}$ pumping power for $0.15 \mathrm{~L} / \mathrm{min}$ and $0.20 \mathrm{~L} / \mathrm{min}$ flow rate, respectively.

Table.4 Comparison of pressure drop, pumping power, temperature difference and maximum temperature using different flow rates

\begin{tabular}{cccccc}
\hline Flow rate (L/min) & $\boldsymbol{\Delta P}(\mathbf{P a})$ & Pumping Power $(\mathbf{W})$ & $\boldsymbol{T}_{\text {diff }}\left({ }^{\circ} \mathrm{C}\right)$ & $\boldsymbol{T}_{\boldsymbol{m a x}}\left({ }^{\circ} \mathrm{C}\right)$ & $\boldsymbol{T}_{\text {uni }}$ \\
\hline 0.05 & 7.03 & $3.66 \mathrm{e}-7$ & 2.18 & 29.20 & 0.076 \\
0.10 & 15.8 & $1.64 \mathrm{e}-6$ & 1.31 & 28.32 & 0.047 \\
0.15 & 27.4 & $4.28 \mathrm{e}-6$ & 0.97 & 27.98 & 0.035 \\
0.20 & 41.8 & $8.69 \mathrm{e}-6$ & 0.80 & 27.81 & 0.029 \\
\hline
\end{tabular}




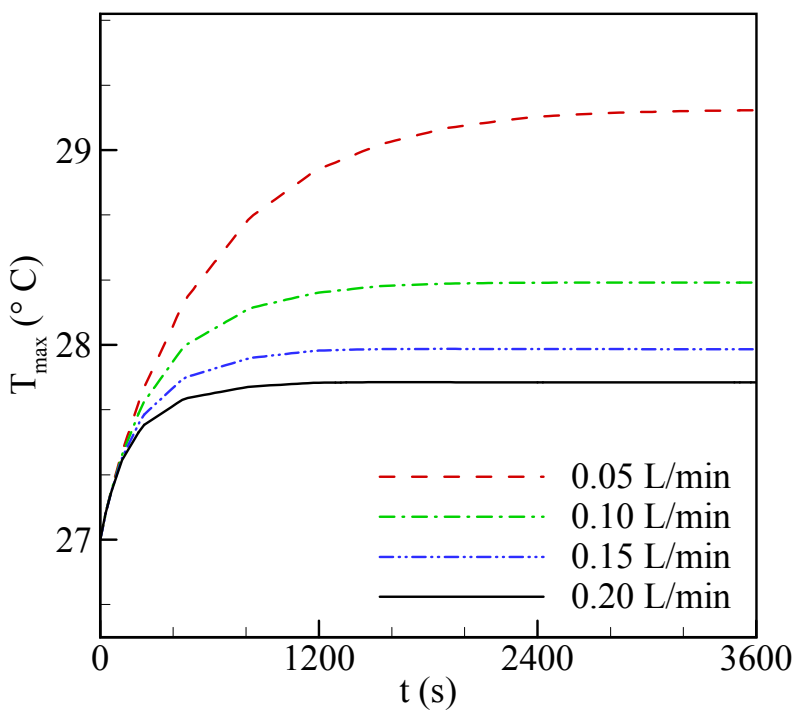

(a)

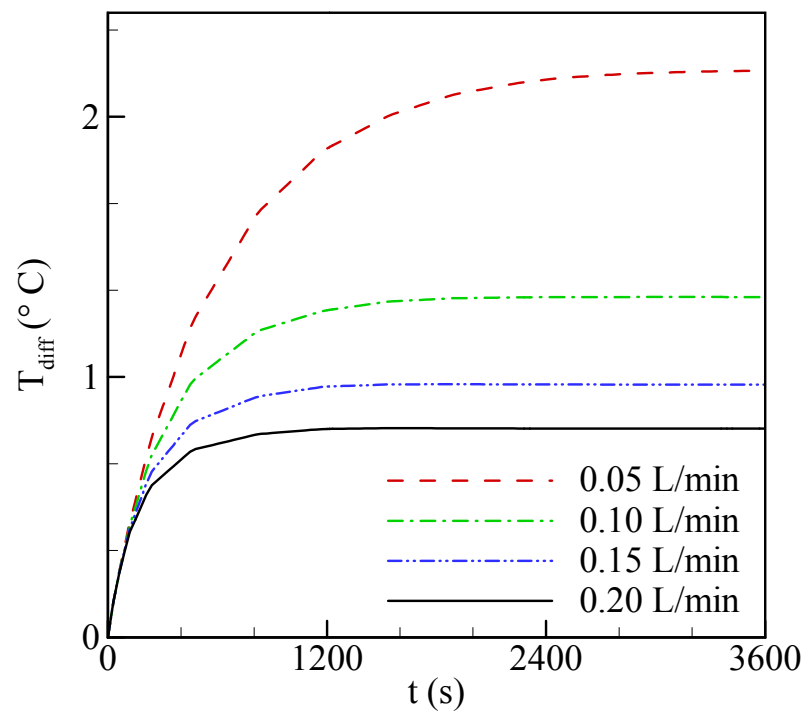

(b)

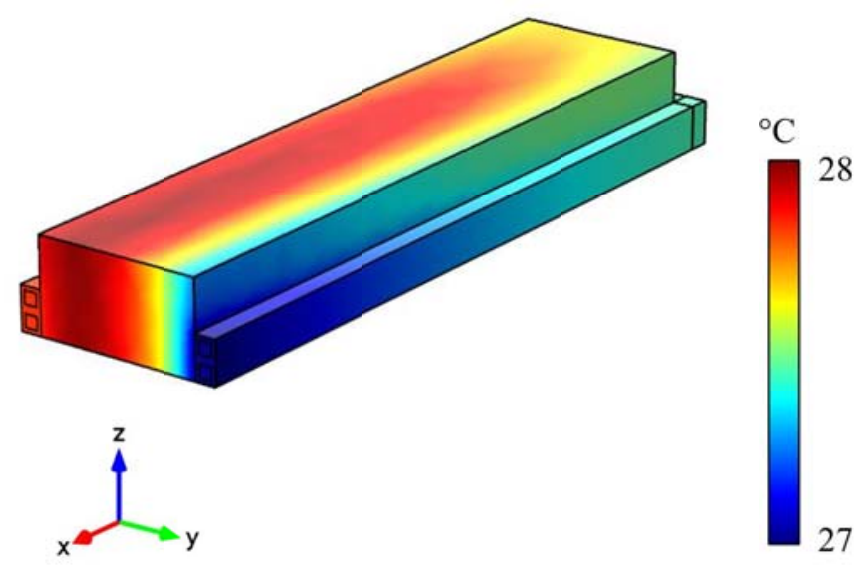

(c)

Fig.5 Temporal history of (a) maximum temperature and (b) temperature difference using different flow rates, at discharge rate of $1 \mathrm{C}\left(Q_{b}=7.60 \mathrm{~W}\right)$. (c) Temperature distribution after 1 hour of discharging at $1 \mathrm{C}\left(Q_{b}=7.60 \mathrm{~W}\right)$, using flow rate as $0.20 \mathrm{~L} / \mathrm{min}$.

\subsection{Thermal management at discharge rate of $1.5 \mathrm{C}\left(Q_{b}=15.60 \mathrm{~W}\right)$}

In this subsection, the thermal performance for a higher discharge rate at $1.5 \mathrm{C}\left(Q_{b}=15.60 \mathrm{~W}\right)$ is studied. Based on the results in Subsection 3.1, flow rates higher than $0.20 \mathrm{~L} / \mathrm{min}$ are used. The results are shown 
in Fig.6. Both $T_{\max }$ and $T_{\text {diff }}$ decrease as the flow rate increases, however the effect of flow rate on cooling performance gets smaller as flow rate increases. From Fig.6(c), it can be seen that the high temperature area of the battery is near the center of battery in cross-plane $(y)$ direction, slightly closer to the minichannel outlet. Due to the high flow rates used, the outlet temperature of the minichannel is much lower than the maximum temperature of the battery. When the flow rate increases from $0.20 \mathrm{~L} / \mathrm{min}$ to $0.40 \mathrm{~L} / \mathrm{min}$, the $T_{\max }$ drops from $28.66^{\circ} \mathrm{C}$ to $28.16^{\circ} \mathrm{C}$ at $2400 \mathrm{~s}$. When the flow rate is further increased to $0.6 \mathrm{~L} / \mathrm{min}, T_{\max }$ reduces to $28.01{ }^{\circ} \mathrm{C}$. Finally, when flow rate increases from $0.80 \mathrm{~L} / \mathrm{min}$ to $1.00 \mathrm{~L} / \mathrm{min}$, the $T_{\max }$ only reduces $0.04{ }^{\circ} \mathrm{C}$ and $T_{\text {uni }}$ only reduces $3 \%$ while the required pumping power increases nearly twice as shown in Table.5. There is no more potential benefit by increasing the flow rate further, since the heat conduction rate inside the battery is limited by the material property and the maximum temperature cannot be reduced anymore by minichannel cooling system. This will be explained in more details in subsection 3.3. Concerning about the pumping power cost, $0.80 \mathrm{~L} / \mathrm{min}$ is the best option for cooling performance at discharge rate of $1.5 \mathrm{C}\left(Q_{b}=15.60 \mathrm{~W}\right)$.

Table.5 Comparison of pressure drop, pumping power, temperature difference and maximum temperature using different flow rates at discharge rate of $1.5 \mathrm{C}\left(Q_{b}=15.60 \mathrm{~W}\right)$

\begin{tabular}{cccccc}
\hline Flow rate (L/min) & $\boldsymbol{\Delta P}(\mathbf{P a})$ & $\boldsymbol{P}$ Pumping Power $(\mathbf{W})$ & $\boldsymbol{T}_{\text {diff }}\left({ }^{\circ} \mathrm{C}\right)$ & $\boldsymbol{T}_{\boldsymbol{m a x}}\left({ }^{\circ} \mathrm{C}\right)$ & $\boldsymbol{T}_{\text {uni }}$ \\
\hline 0.20 & 41.8 & $8.74 \mathrm{e}-6$ & 1.65 & 28.66 & 0.058 \\
0.40 & 160 & $6.66 \mathrm{e}-5$ & 1.15 & 28.16 & 0.041 \\
0.60 & 314 & $1.96 \mathrm{e}-4$ & 1.00 & 28.01 & 0.036 \\
0.80 & 508 & $4.23 \mathrm{e}-4$ & 0.94 & 27.94 & 0.034 \\
1.00 & 743 & $7.74 \mathrm{e}-4$ & 0.90 & 27.90 & 0.033 \\
\hline
\end{tabular}




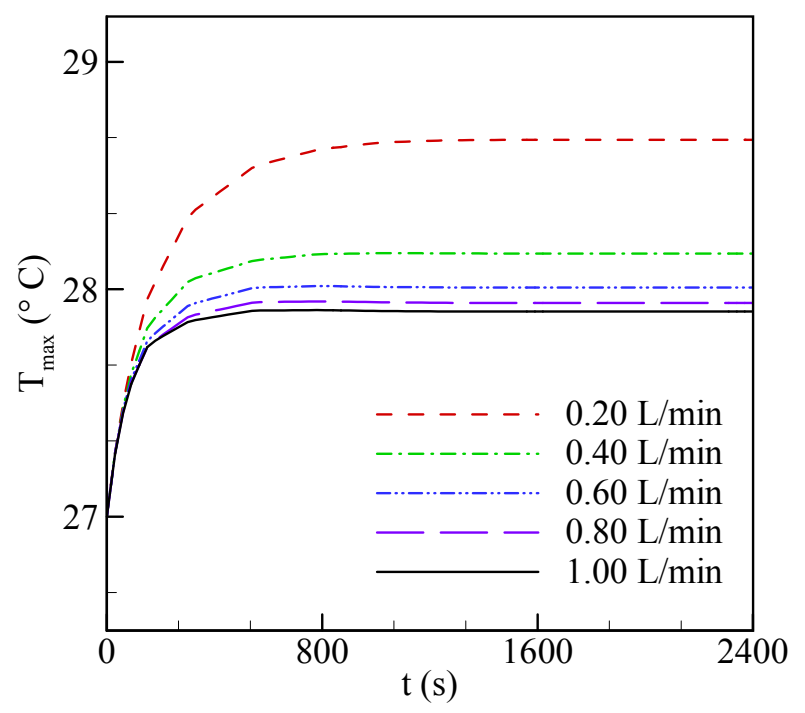

(a)

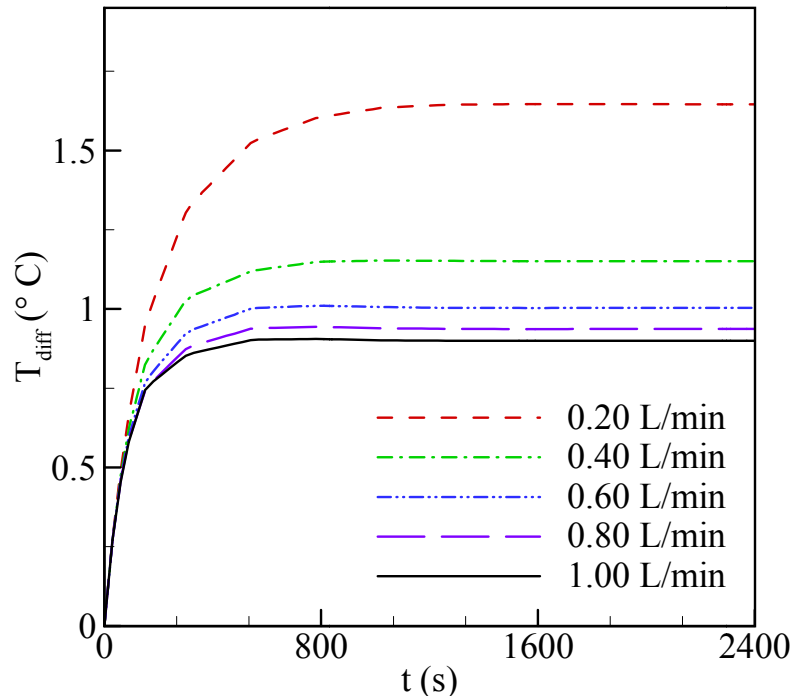

(b)

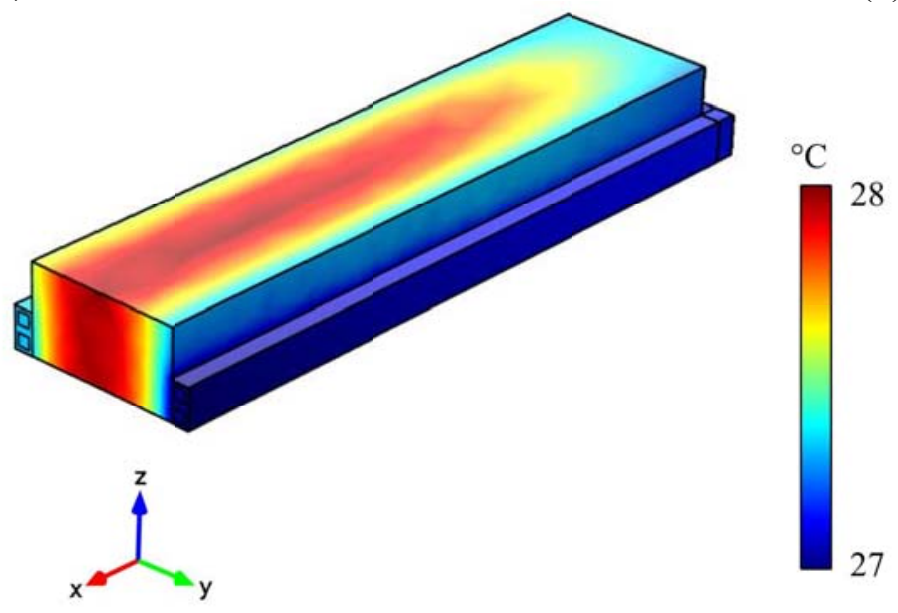

(c)

Fig.6 Temporal history of (a) maximum temperature and (b) temperature difference using different flow rates, at discharge rate of $1.5 \mathrm{C}\left(Q_{b}=15.60 \mathrm{~W}\right)$. (c) Temperature distribution after $2400 \mathrm{~s}$ of discharging at $1.5 \mathrm{C}\left(Q_{b}=\right.$ $15.60 \mathrm{~W})$, using flow rate as $1.00 \mathrm{~L} / \mathrm{min}$.

\subsection{Thermal management at discharge rate of $2 \mathrm{C}\left(Q_{b}=23.89 \mathrm{~W}\right)$}

A harsher situation is studied in this subsection as the discharge rate increases to $2 \mathrm{C}\left(Q_{b}=23.89 \mathrm{~W}\right)$. According to previous discussion for discharge rate of $1.5 \mathrm{C}\left(Q_{b}=15.60 \mathrm{~W}\right)$, flow rates no less than 1.00 $\mathrm{L} / \mathrm{min}$ are used for the cooling system performance analysis. 


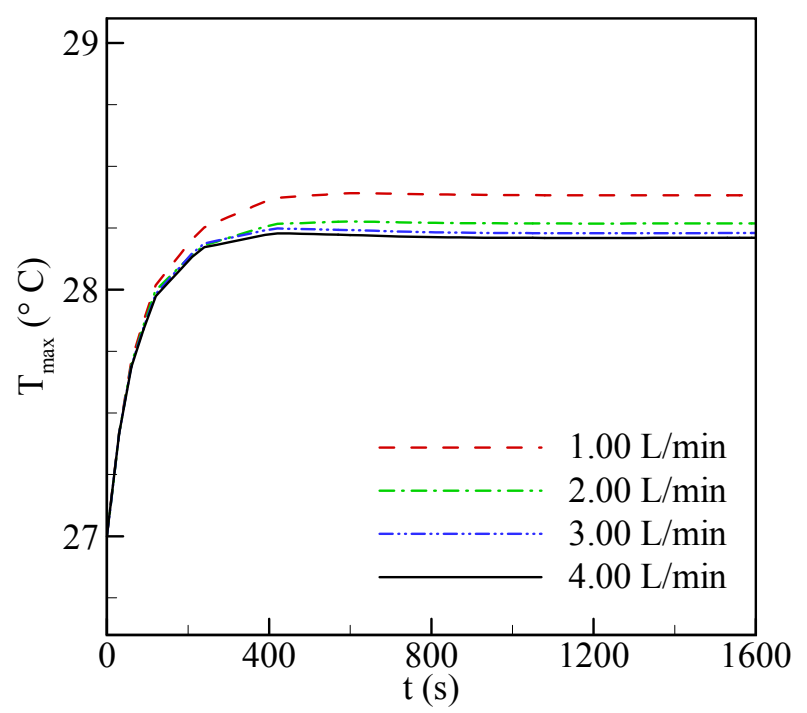

(a)

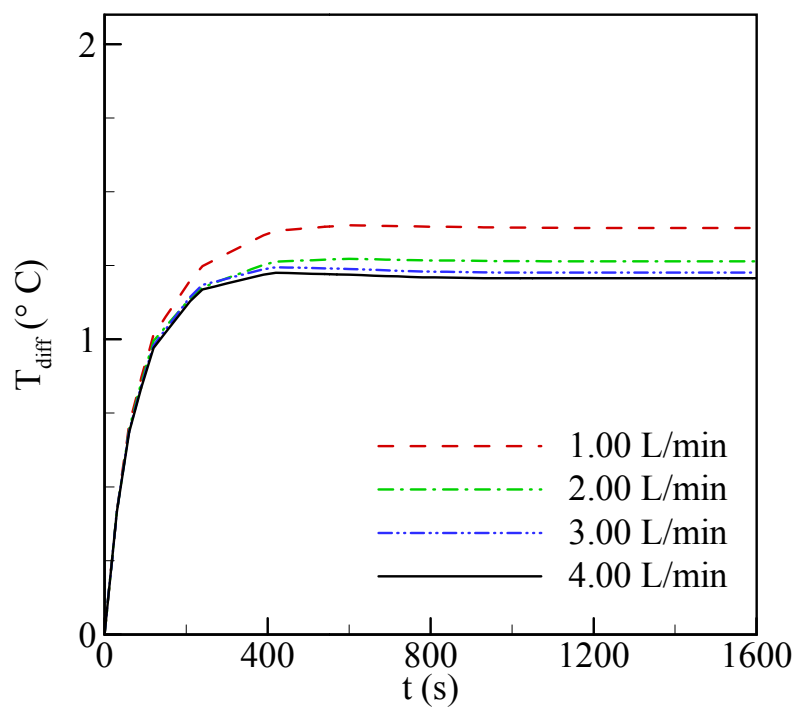

(b)

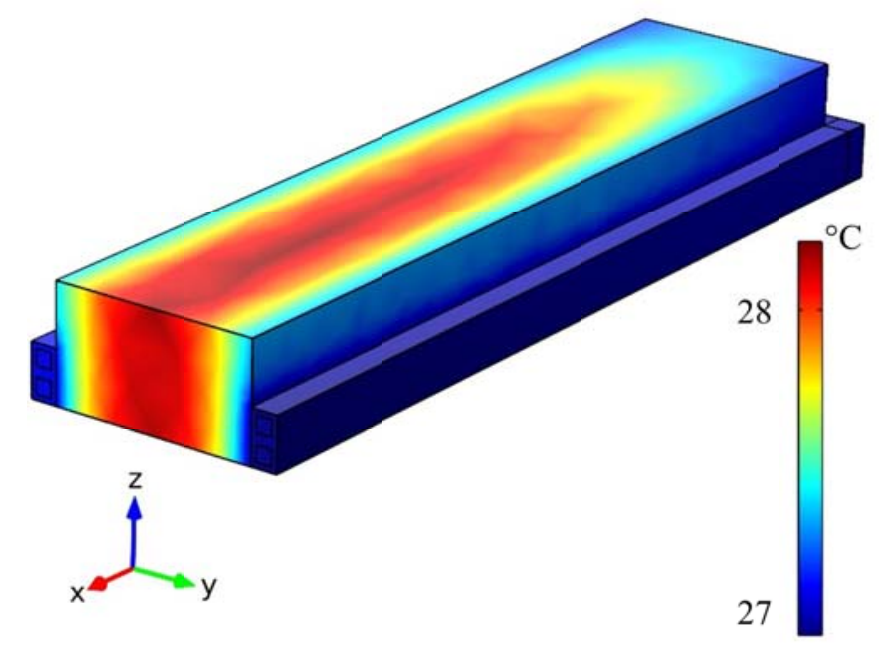

(c)

Fig.7 Temporal history of (a) maximum temperature and (b) temperature difference using different higher flow rates, at discharge rate of $2 \mathrm{C}\left(Q_{b}=23.89 \mathrm{~W}\right)$. (c) Temperature distribution of battery and minichannels after 1800s of discharging at $2 \mathrm{C}\left(Q_{b}=23.89 \mathrm{~W}\right)$, using flow rate as $4.00 \mathrm{~L} / \mathrm{min}$.

Results for $T_{\max }$ and $T_{\text {diff }}$ using different flow rates at discharge rate of $2 \mathrm{C}\left(Q_{b}=23.89 \mathrm{~W}\right)$ are shown in Fig.7, respectively. At flow rate of $1.00 \mathrm{~L} / \mathrm{min}, T_{\max }$ reaches to $28.38{ }^{\circ} \mathrm{C}$. As flow rate increases to 2.00 $\mathrm{L} / \mathrm{min}, T_{\max }$ reduces to $28.27^{\circ} \mathrm{C}$, but the required pumping power becomes seven times larger (Table.6). 
When flow rate increases further to $4.00 \mathrm{~L} / \mathrm{min}$, there is not much improvement for cooling performance as $T_{\max }, T_{\text {diff }}$ and $T_{u n i}$ almost keep unchanged. However, the pumping power is doubled to $3.61 \mathrm{e}-2 \mathrm{~W}$. Concerning about the pumping power cost, $2.00 \mathrm{~L} / \mathrm{min}$ is the best option for cooling performance at discharge rate of $2 \mathrm{C}\left(Q_{b}=23.89 \mathrm{~W}\right)$.

To further explore the cooling system improvement using higher flow rate, the temperature contour of battery and minichannels using flow rate as $4.00 \mathrm{~L} / \mathrm{min}$ is shown in Fig.7(c). The temperature of minichannels is quite low at both inlet and outlet, due to the large flow rate. The maximum battery temperature is at the center of battery in the $y$ (depth) direction, due to the low cross-plane thermal conductivity of the battery. Though the heat can be quickly taken away by the large flow rate, the heat transfer inside the battery is constraint by the (cross-plane) thermal conductivity of material and the geometrical thickness in that cross-plane (y) direction. Increasing flow rates for minichannels is not an effective solution for this high discharge rate. However reducing the thickness in the cross-plane (y) direction should be an applicable solution. Though there is no much room for the improvement for cooling performance, maintaining $T_{\max }$ as low as $28.38{ }^{\circ} \mathrm{C}$ and $T_{\text {diff }}$ as low as $1.38{ }^{\circ} \mathrm{C}$ is still acceptable for thermal management performance.

Table.6 Comparison of pressure drop, pumping power, temperature difference and maximum temperature using different flow rates at discharge rate of $2 \mathrm{C}\left(Q_{b}=23.89 \mathrm{~W}\right)$

\begin{tabular}{cccccc}
\hline Flow rate (L/min) & $\boldsymbol{\Delta P}(\mathbf{P a})$ & $\boldsymbol{P o w e r}(\mathbf{W})$ & $\boldsymbol{T}_{\text {diff }}\left({ }^{\circ} \mathrm{C}\right)$ & $\boldsymbol{T}_{\boldsymbol{m a x}}\left({ }^{\circ} \mathrm{C}\right)$ & $\boldsymbol{T}_{\text {uni }}$ \\
\hline 1.00 & 743 & $7.74 \mathrm{e}-4$ & 1.38 & 28.38 & 0.049 \\
2.00 & $2.53 \mathrm{k}$ & $5.27 \mathrm{e}-3$ & 1.26 & 28.27 & 0.045 \\
3.00 & $5.19 \mathrm{k}$ & $1.63 \mathrm{e}-2$ & 1.23 & 28.23 & 0.044 \\
4.00 & $8.66 \mathrm{k}$ & $3.61 \mathrm{e}-2$ & 1.21 & 28.21 & 0.044 \\
\hline
\end{tabular}




\section{Conclusion}

Parametric studies were carried out to demonstrate the feasibility of adopting the minichannels cooling system for high-capacity lithium-ion battery thermal management. Effects of different geometric designs, flow directions, and flow rates, were studied through parametric study by monitoring maximum temperature rise of the battery $T_{\max }$, temperature difference across the battery $T_{\text {diff }}$ and temperature uniformity $T_{u n i}$. Under the same total flow rate inside the cooling system, the more minichannels are used, the better cooling performance can be achieved, though the inlet flow speed is reduced accordingly. Additionally, with same total number of minichannels, the case using distributed distribution of minichannels shows better cooling performance than the case using concentrated distribution. Moreover, the effects of the flow rate and flow direction were studied. Results indicate that the best performance is achieved when all the flow inlets are aligned at one side of battery, instead of alternative inlets and outlets.

In addition, this study shows that at discharge rate of $1 \mathrm{C}$, using flow rate of $0.20 \mathrm{~L} / \mathrm{min}, T_{\max }$ is well controlled at $27.81{ }^{\circ} \mathrm{C}$ and $T_{\text {diff }}$ is $0.80{ }^{\circ} \mathrm{C}$ after 1 hour of discharging, with only 8.69e-6 W pumping power required. At discharge of $1.5 \mathrm{C}$, as flow rate increases to $0.80 \mathrm{~L} / \mathrm{min}$, the $T_{\max }$ is $27.94{ }^{\circ} \mathrm{C}$. Because only slight improvement on cooling performance can be achieved using flow rates higher than $0.80 \mathrm{~L} / \mathrm{min}$, $0.80 \mathrm{~L} / \mathrm{min}$ is adopted as the best option for cooling performance at discharge rate of $1.5 \mathrm{C}$, considering the concerns about the pumping power cost for higher flow rates. When discharge rate increases to $2 \mathrm{C}$, at flow rate of $1.00 \mathrm{~L} / \mathrm{min}, T_{\max }$ reaches to $28.27{ }^{\circ} \mathrm{C}$ and $T_{\text {diff }}$ is $1.26{ }^{\circ} \mathrm{C}$, with $5.27 \mathrm{e}-3 \mathrm{~W}$ pumping power required. Further increase in flow rate cannot reduce the temperature near the battery center in cross-plane (y) direction, but only can reduce the water temperature at the outlet.

In conclusion, we have demonstrated that the minichannels cooling system can be applied for the battery thermal management. This system can reduce both the maximum temperature rise and temperature difference across the whole battery, at little expense of pressure drop and pumping power. 


\section{Acknowledgement}

This work was funded by the United States Department of Energy under the ARPA-E program (Award No.

DEAR0000396)

\section{Reference}

[1] Available: http://www.epa.gov/climatechange/ghgemissions/global.html

[2] J. Tollefson, "Charging up the future," Nature, vol. 456, pp. 436-440, 2008.

[3] S. F. Tie and C. W. Tan, "A review of energy sources and energy management system in electric vehicles," Renewable and Sustainable Energy Reviews, vol. 20, pp. 82-102, 2013.

[4] T. M. Bandhauer, et al., "A Critical Review of Thermal Issues in Lithium-Ion Batteries," Journal of the Electrochemical Society, vol. 158, pp. R1-R25, 2011.

[5] L. G. Lu, et al., "A review on the key issues for lithium-ion battery management in electric vehicles," Journal of Power Sources, vol. 226, pp. 272-288, Mar 152013.

[6] Z. H. Rao and S. F. Wang, "A review of power battery thermal energy management," Renewable \& Sustainable Energy Reviews, vol. 15, pp. 4554-4571, Dec 2011.

[7] Q. Wang, et al., "Thermal runaway caused fire and explosion of lithium ion battery," Journal of Power Sources, vol. 208, pp. 210-224, 2012.

[8] R. Spotnitz and J. Franklin, "Abuse behavior of high-power, lithium-ion cells," Journal of Power Sources, vol. 113, pp. 81-100, 2003.

[9] P. Balakrishnan, et al., "Safety mechanisms in lithium-ion batteries," Journal of Power Sources, vol. 155, pp. 401-414, 2006.

[10] L. Lu, et al., "A review on the key issues for lithium-ion battery management in electric vehicles," Journal of Power Sources, vol. 226, pp. 272-288, 2013.

[11] A. A. Pesaran, "Battery thermal models for hybrid vehicle simulations," Journal of Power Sources, vol. 110, pp. 377-382, 2002.

[12] S. Chen, et al., "Thermal analysis of lithium-ion batteries," Journal of Power Sources, vol. 140, pp. 111-124, 2005.

[13] T. Hatchard, et al., "Thermal model of cylindrical and prismatic lithium-ion cells," Journal of the Electrochemical Society, vol. 148, pp. A755-A761, 2001.

[14] G.-H. Kim, et al., "A three-dimensional thermal abuse model for lithium-ion cells," Journal of Power Sources, vol. 170, pp. 476-489, 2007.

[15] G. Guo, et al., "Three-dimensional thermal finite element modeling of lithium-ion battery in thermal abuse application," Journal of Power Sources, vol. 195, pp. 2393-2398, 2010.

[16] K. Smith and C.-Y. Wang, "Power and thermal characterization of a lithium-ion battery pack for hybrid-electric vehicles," Journal of Power Sources, vol. 160, pp. 662-673, 2006.

[17] H. Sun, et al., "Three-dimensional thermal modeling of a lithium-ion battery pack," Journal of Power Sources, vol. 206, pp. 349-356, 2012.

[18] C.-H. Doh, et al., "Thermal and electrochemical behaviour of C/Li x $\mathrm{CoO} 2$ cell during safety test," Journal of Power Sources, vol. 175, pp. 881-885, 2008.

[19] K.-C. Chiu, et al., "An electrochemical modeling of lithium-ion battery nail penetration," Journal of Power Sources, vol. 251, pp. 254-263, 2014. 
[20] U. S. Kim, et al., "Modelling the thermal behaviour of a lithium-ion battery during charge," Journal of Power Sources, vol. 196, pp. 5115-5121, 2011.

[21] M.-S. Wu, et al., "Heat dissipation design for lithium-ion batteries," Journal of Power Sources, vol. 109, pp. 160-166, 2002.

[22] X. Xu and R. He, "Review on the heat dissipation performance of battery pack with different structures and operation conditions," Renewable and Sustainable Energy Reviews, vol. 29, pp. 301-315, 2014.

[23] R. Mahamud and C. Park, "Reciprocating air flow for Li-ion battery thermal management to improve temperature uniformity," Journal of Power Sources, vol. 196, pp. 5685-5696, 2011.

[24] T. Wang, et al., "Thermal investigation of lithium-ion battery module with different cell arrangement structures and forced air-cooling strategies," Applied Energy, vol. 134, pp. 229-238, 2014.

[25] S. K. Mohammadian and Y. Zhang, "Thermal management optimization of an air-cooled Li-ion battery module using pin-fin heat sinks for hybrid electric vehicles," Journal of Power Sources, vol. 273, pp. 431-439, 2015.

[26] L. Fan, et al., "A parametric study on thermal management of an air-cooled lithium-ion battery module for plug-in hybrid electric vehicles," Journal of Power Sources, vol. 238, pp. 301-312, 2013.

[27] R. Sabbah, et al., "Active (air-cooled) vs. passive (phase change material) thermal management of high power lithium-ion packs: Limitation of temperature rise and uniformity of temperature distribution," Journal of Power Sources, vol. 182, pp. 630-638, 2008.

[28] S. Al Hallaj and J. Selman, "A Novel Thermal Management System for Electric Vehicle Batteries Using Phase - Change Material," Journal of the Electrochemical Society, vol. 147, pp. 3231-3236, 2000.

[29] S. Al-Hallaj and J. Selman, "Thermal modeling of secondary lithium batteries for electric vehicle/hybrid electric vehicle applications," Journal of Power Sources, vol. 110, pp. 341-348, 2002.

[30] R. Kizilel, et al., "An alternative cooling system to enhance the safety of Li-ion battery packs," Journal of Power Sources, vol. 194, pp. 1105-1112, 2009.

[31] Z. Rao and S. Wang, "A review of power battery thermal energy management," Renewable and Sustainable Energy Reviews, vol. 15, pp. 4554-4571, 2011.

[32] Y. Zhang, et al., "Thermal performance study of integrated cold plate with power module," Applied Thermal Engineering, vol. 29, pp. 3568-3573, 2009.

[33] L. Jin, et al., "Ultra-thin minichannel LCP for EV battery thermal management," Applied Energy, vol. 113, pp. 1786-1794, 2014.

[34] Y. Huo, et al., "Investigation of power battery thermal management by using mini-channel cold plate," Energy Conversion and Management, vol. 89, pp. 387-395, 2015.

[35] X. Xie, et al., "Numerical study of laminar heat transfer and pressure drop characteristics in a water-cooled minichannel heat sink," Applied Thermal Engineering, vol. 29, pp. 64-74, 2009.

[36] J. P. Rugh, et al., "Electric Vehicle Battery Thermal Issues and Thermal Management Techniques," presented at the SAE 2011 Alternative Refrigerant and System Efficiency Syposium, 2011.

[37] R. K. Shah and A. L. London, Laminar flow forced convection in ducts: a source book for compact heat exchanger analytical data vol. 1: Academic press, 1978.

[38] D. Liu and S. V. Garimella, "Investigation of liquid flow in microchannels," Journal of Thermophysics and heat transfer, vol. 18, pp. 65-72, 2004.

[39] M. V. Koch, et al., Micro instrumentation: for high throughput experimentation and process intensification-a tool for PAT: John Wiley \& Sons, 2007. 